\title{
Effects of high-flux hemodialysis combined with levocarnitine on vascular calcification, microinflammation, hepcidin, and malnutrition of elderly patients on maintenance hemodialysis
}

\author{
Xiang-Geng $\mathrm{Chi}^{1 \#}$, Zhen $\mathrm{Ma}^{2 \#}$, Wen-Bin Zhang ${ }^{1}$, Qi Cai ${ }^{1}$, Yan-Zhuan Chen ${ }^{1}$, De-Liang Ding ${ }^{1}$ \\ ${ }^{1}$ Department of Nephrology, The Affiliated Xiaolan Hospital of Southern Medical University, Zhongshan, China; ${ }^{2}$ Department of Nephrology, \\ Guangzhou Hospital of Integrated Chinese and Western Medicine, Guangzhou, China \\ Contributions: (I) Conception and design: XG Chi, Z Ma; (II) Administrative support: WB Zhang, Q Cai, YZ Chen; (III) Provision of study materials \\ or patients: Z Ma, DL Ding; (IV) Collection and assembly of data: XG Chi, WB Zhang; (V) Data analysis and interpretation: XG Chi, Z Ma; (VI) \\ Manuscript writing: All authors; (VII) Final approval of manuscript: All authors. \\ "These authors contributed equally to this work. \\ Correspondence to: De-Liang Ding. Department of Nephrology, The Affiliated Xiaolan Hospital of Southern Medical University, No. 65 Jucheng \\ Avenue, Xiaolan, Zhongshan 528415, China. Email: DLDing066@126.com.
}

\begin{abstract}
Background: This study was to investigate the effect of high-flux hemodialysis (HD) combined with levocarnitine on vascular calcification, microinflammation, hepcidin, and malnutrition in elderly patients on maintenance HD (MHD).

Methods: 75 MHD elderly patients admitted to hospital between $1^{\text {st }}$ September 2017 and $31^{\text {st }}$ August 2019 were selected as the study subjects. They were randomly divided by digital table into three groups: low-flux group ( $\mathrm{n}=25)$, high-flux group $(\mathrm{n}=25)$ and joint group $(\mathrm{n}=25)$. In the low-flux group, dialyzer had an ultrafiltration coefficient $12 \mathrm{~mL} /(\mathrm{h} \cdot \mathrm{mmHg})$ and effective surface area of $1.4 \mathrm{~m}^{2}$ compared with $59 \mathrm{~mL} /(\mathrm{h} \cdot \mathrm{mmHg})$ and $1.8 \mathrm{~m}^{2}$ in the high-flux group. After treatment, the calcification of blood vessels was examined by lateral X-ray, pelvic plain film and bilateral positive position. For patients in all groups, the concentrations of parathyroid hormone (PTH) and $\beta$ 2-microglobulin ( $\beta$ 2-MG) in serum were measured by automatic chemiluminescence; levels of interleukin-6, C-reactive protein (CRP), and tumor necrosis factor alpha (TNF- $\alpha$ ) were measured by ELISA before and after treatment; and the level of hepcidin was measured by ELISA. Before and 12 weeks after the treatment, the nutritional status of the patients was evaluated by modified quantitative subjective global assessment (MQSGA), hemoglobin ( $\mathrm{Hb}$ ) and red blood cell count (RBC). Complications in the three groups were recorded, including nausea, chest pain, hypotension, hypertension, pruritus, dry heat, muscle spasm, arrhythmia, and restless legs.
\end{abstract}

Results: Vascular calcification in the joint group was better than the low-flux and high-flux groups $(\mathrm{P}<0.05)$. After treatment, the serum PTH and $\beta$ 2-mg concentrations in the joint group were lower than those in the other two groups $(\mathrm{P}<0.05)$, and the levels of IL-6, CRP, TNF- $\alpha$ and hepcidin in the joint group were significantly lower than those before treatment $(\mathrm{P}<0.05)$. After treatment, the MQSGA scores in the joint group were lower than those in the low-flux and high-flux groups $(\mathrm{P}<0.05)$, and $\mathrm{Hb}$ and $\mathrm{RBC}$ were higher $(\mathrm{P}<0.05)$.

Conclusions: The combination of high-flux HD and levocarnitine in elderly patients on MHD can increase the clearance of medium and large molecular toxins, effectively correct malnutrition, alleviate microinflammation, delay the progress of vascular calcification, and is safe.

Keywords: Hepcidin; high-flux hemodialysis; low-flux hemodialysis; microinflammation; vascular calcification

Submitted Dec 10, 2020. Accepted for publication Mar 24, 2021.

doi: 10.21037/apm-21-66

View this article at: http://dx.doi.org/10.21037/apm-21-66 


\section{Introduction}

Maintenance hemodialysis (MHD) is one of the main treatments for endstage renal disease (ESRD). It is a lifelong replacement therapy. In recent years, the incidence of diabetes, hypertension, obesity and other risk factors for ESRD has been increasing, and the number of patients receiving MHD are increasing year by year with the acceleration of aging $(1,2)$. Even if MHD is an effective treatment for ESRD, inflammation, various degrees of malnutrition and renal anemia have a serious effect on patients' quality of life (QOL) (3). L-carnitine, also known as $\mathrm{L}-\mathrm{CN}$, is a special amino acid that is essential for fat metabolism. Due to reduced intake and dialysis clearance, patients with MHD suffer from a general lack of L-CN, aggravating complications such as dialysis hypotension, myocardial damage, malnutrition, and renal anemia (4). Bodily functions deteriorate gradually with age, so elderly patients on MHD are especially prone to the effects of a lack of L-CN (5).

Therefore, improving the quality of dialysis for elderly patients and reducing dialysis complications is an urgent task both clinically and in research. At present, there are a variety of drugs that can improve the complications of HD patients, but most of them are symptomatic drugs that improve single complications. The application of L-CN can improve dialysis hypotension, myocardial damage, malnutrition, renal anemia and other complications. It is effective and may prevent complications through pre-administration of L-CN. In the present study we investigated the effects of high-flux HD combined with levocarnitine on vascular calcification, microinflammation, hepcidin levels, and malnutrition of elderly patients on MHD, aiming to provide information for better clinical treatment of these patients. We present the following article in accordance with the CONSORT reporting checklist (available at http://dx.doi.org/10.21037/apm-21-66).

\section{Methods}

\section{Baseline information}

The study group of 75 elderly patients on MHD admitted to hospital between September 2017 and July 2019 were randomly divided by numeration table into three groups: low-flux HD group ( $n=25)$, a high flux HD group $(n=25)$, and a joint group $(n=25)$. Inclusion criteria were: (I) complying with the diagnostic criteria of the NKF-K/ DOQI guidelines in the USA for chronic kidney disease, meeting the indication for MHD treatment of hemoglobin $(\mathrm{Hb})<120 \mathrm{~g} / \mathrm{L}$ (male) and $\mathrm{Hb}<110 \mathrm{~g} / \mathrm{L}$ (female), and able to undergo MHD in hospital; (II) age $\geq 60$ years; (III) duration of $\mathrm{MHD} \geq 2$ years; (IV) duration of lowflux $M H D \geq 3$ months; (V) absence of severe infection or heart failure, antibiotic treatment, active diseases, and malignant tumors in the past 3 months; (VI) taking lowmolecular-weight heparin calcium anticoagulation; (VII) undergoing three 4-h dialysis treatment per week and blood flow of 200-300 mL/min; (VIII) smooth blood circulation during dialysis, reaching or approaching the dry body mass; (IX) good treatment compliance and being able to follow medical staff instructions and sign informed consent. The exclusion criteria were: (I) use of glucocorticoids or immunosuppressants in the past 3 months; (II) bleeding or blood transfusion or taking antibiotics in the past 3 months; (III) hematologic disease; (IV) acute or chronic infection; (V) severe malnutrition; (VI) malignant tumors; (VII) severe heart failure or multiple organ failure; (VIII) sepsis, chronic hepatitis, tuberculosis, systemic lupus erythematosus, vasculitis, liver insufficiency, epilepsy, a family history of epilepsy; and (IX) blood flow during dialysis $<200 \mathrm{~mL} / \mathrm{min}$. Sex, age, and disease classification among the three groups were comparable without statistical significance $(\mathrm{P}>0.05)$, as shown in Table 1. All procedures performed in this study involving human participants were in accordance with the Declaration of Helsinki (as revised in 2013). Informed consent was taken from all the patients. The study was approved by institutional ethics committee of The Affiliated Xiaolan Hospital of Southern Medical University (No. 201709).

\section{Equipment}

The Fresenius 4008s hemodialysis machine (Fresenius Medical Care, Germany), H1650 desktop high-speed centrifuge (Xiangyi Instrument Co., Ltd., Hunan, China), 7060 automatic biochemical analyzer (Hitachi, Japan), Roche Cobas E601 electroluminescence analyzer (Roche, Switzerland), and Dia Sorin Liaison 4000 chemiluminescence instrument (Sorin, Italy) were used. AQUABOSS RO Dia II 2000 water treatment system (Lauer, Germany), dialysate (calcium concentration of $1.5 \mathrm{mmol} / \mathrm{L}$ ), interleukin (IL)-6, tumor necrosis factor alpha (TNF- $\alpha)$, and C-reactive protein (CRP) ELISA kits (batch no. T1200-100, 090M01549V, and LJ0728B1009J), hepcidin ELISA kit (TSZ, USA) were used. Levocarnitine $(0.1 \mathrm{~g} / \mathrm{kg} /$ day) (Northeast Pharm in Liaoning Province of China, SFDA approval no. H20113215, specification: 
Table 1 Comparison of baseline information of elderly patients on maintenance hemodialysis (HD)

\begin{tabular}{|c|c|c|c|}
\hline Variable & Joint $(n=25)$ & $\begin{array}{l}\text { High-flux HD } \\
\quad(n=25)\end{array}$ & $\begin{array}{c}\text { Low-flux HD } \\
(n=25)\end{array}$ \\
\hline \multicolumn{4}{|l|}{ Sex, n (\%) } \\
\hline Male & $14(0.56)^{a, b}$ & $15(0.60)$ & $13(0.52)$ \\
\hline Female & $11(0.44)^{a, b}$ & $10(0.40)$ & $12(0.48)$ \\
\hline Average age (years) & $71.08 \pm 9.18^{a}$ & $71.20 \pm 6.31^{b}$ & $71.32 \pm 7.12$ \\
\hline \multicolumn{4}{|c|}{ Disease classification, n (\%) } \\
\hline $\begin{array}{l}\text { Chronic } \\
\text { glomerulonephritis }\end{array}$ & $9(0.36)^{\mathrm{a}}$ & $8(0.32)^{b}$ & $7(0.28)$ \\
\hline Diabetic nephropathy & $6(0.24)^{a}$ & $5(0.20)^{b}$ & $6(0.24)$ \\
\hline $\begin{array}{l}\text { Hypertensive kidney } \\
\text { lesion }\end{array}$ & $4(0.16)^{\mathrm{a}}$ & $5(0.20)^{b}$ & $4(0.16)$ \\
\hline Polycystic kidney & $3(0.12)^{a}$ & $4(0.16)^{b}$ & $4(0.16)$ \\
\hline $\begin{array}{l}\text { Obstructive } \\
\text { nephropathy }\end{array}$ & $3(0.12)^{a}$ & $3(0.12)^{b}$ & $4(0.16)$ \\
\hline
\end{tabular}

Note: compared with high- and low-flux HD groups, ${ }^{\text {a }}, \mathrm{P}>0.05$; compared with low-flux HD group, ${ }^{b}, \mathrm{P}>0.05$.

$1 \mathrm{~g} /$ vial) was used.

\section{Low-flux HD group}

We selected the REXEED ${ }^{\mathrm{TM}}$ (AsahiKASEI, SFDA approval no. 20153450879) 13 polysulfone membrane with an ultrafiltration coefficient of $12 \mathrm{~mL} /(\mathrm{h} \cdot \mathrm{mmHg})$, and effective surface area of $1.4 \mathrm{~m}^{2}$, and a sugar-free bicarbonate dialysate (concentration of calcium, sodium and potassium ions of $1.5,138$, and $2.0 \mathrm{mmol} / \mathrm{L}$ respectively), dialysate flow of $500 \mathrm{~mL} / \mathrm{min}$, and blood flow of $200-300 \mathrm{~mL} / \mathrm{min}$ were used. The dialysate temperature was $36-37^{\circ} \mathrm{C}$, the ambient temperature was $22-24^{\circ} \mathrm{C}$, and the autogenous arteriovenous fistula was used as the blood channel. Dialysis was performed three times per week for $4 \mathrm{~h}$ each time.

\section{High-flux HD group}

We selected the $15 \mathrm{UC}$ polysulfone membrane (AsahiKASEI) with an ultrafiltration coefficient of $59 \mathrm{~mL} /(\mathrm{h} \cdot \mathrm{mmHg})$, and effective surface area of $1.8 \mathrm{~m}^{2}$. The same sugar-free bicarbonate dialysate as for the low-flux HD group was used, the dialysate flow was $500 \mathrm{~mL} / \mathrm{min}$, blood flow 200-300 was $\mathrm{mL} / \mathrm{min}$, dialysate and ambient temperatures were the same as for the low-flux HD group, and the autogenous arteriovenous fistula was used as the blood channel. Dialysis was performed three times per week for $4 \mathrm{~h}$ each time, which lasts for one month.

\section{High-flux HD + levocarnitine (combination group)}

The dialysis method and protocol were the same as for the high-flux HD group, but $1 \mathrm{~g}$ of levocarnitine + $20 \mathrm{~mL}$ of $0.9 \%$ sodium chloride solution were administered by intravenous injection three times a week at the end of dialysis.

None of the study patients were transfused with blood products, such as albumin and erythrocytes, during treatment. Patients with hypertension were given antihypertensive drugs according to their specific condition, and those with diabetes were given insulin to control blood glucose. Patients with anemia were given folic acid and erythropoietin, and iron was supplemented as appropriate based on the serum indicators.

\section{Observation indicators}

\section{Detection of vascular calcification}

A simple vascular calcification scoring method was used 14 days after treatment, lasting for one month. A plain pelvic radiograph, orthotopic views of both hands, and lateral X-ray of the lumbar spine were taken. The plain pelvic radiograph was divided into four parts with a horizontal line on the femoral heads and a vertical line on the spine. The orthotopic views of the hands were divided into four parts with the upper parts of the metacarpal bones as the horizontal line. The lateral lumbar spine was divided into two parts at the L2 and L3 intervertebral spaces. Thus, there were 10 parts in total. Two radiologists were required to score blindly and individually. Each part was classified as 1 for calcification or 0 for no calcification, and the average value was calculated finally. The total scores were 0 for no calcification, 1-3 for mild calcification, 4-6 for moderate calcification, and 7-10 for severe calcification.

\section{Detection of parathyroid hormone (PTH) and $\beta 2$ - microglobulin ( $\beta 2-M G)$}

Before and 7 days after treatment, $5 \mathrm{~mL}$ of fasting venous blood was collected in an anticoagulation tube, and centrifuged in the H1650 desktop high-speed centrifuge $(5,000 \mathrm{~g}$, centrifugal radius $10 \mathrm{~cm})$ for $10 \mathrm{~min}$ to separate the serum. The 7060 fully automatic biochemical analyzer was used to detect the concentration of serum PTH and $\beta 2-\mathrm{MG}$.

\section{Detection of microinflammation}

ELISA was used to detect the levels of IL-6, CRP, and 
Table 2 Comparison of vascular calcification of patients in three HD groups [n (\%)]

\begin{tabular}{|c|c|c|c|c|c|}
\hline Calcification & Joint $(n=25)$ & High-flux HD ( $n=25)$ & Low-flux HD $(n=25)$ & $\chi^{2}$ & $P$ \\
\hline \multicolumn{6}{|c|}{ Vascular calcification } \\
\hline Mild & $3(0.12)$ & $2(0.08)$ & $4(0.16)$ & & \\
\hline Moderate & $4(0.16)$ & $10(0.40)$ & $8(0.32)$ & & \\
\hline Total & $11(0.44)$ & $20(0.80)$ & $21(0.84)$ & 11.41 & 0.003 \\
\hline
\end{tabular}

$\mathrm{HD}$, hemodialysis.

TNF- $\alpha$ in the serum of patients in all three groups before and 7 days after treatment.

\section{Detection of plasma hepcidin}

ELISA was used to detect the level of plasma hepcidin before and 7 days after treatment in the two groups. A $3-\mathrm{mL}$ sample of fasting venous blood was collected on the current day and the $7^{\text {th }}$ day of physical examination, and the level of plasma hepcidin was measured according to the manufacturer's instructions.

\section{Assessment of malnutrition}

Before and 3 months after treatment, the modified quantitative subjective global assessment (MQSGA), hemoglobin $(\mathrm{Hb})$ and red blood cell count (RBC) were used to assess the nutritional state of the patients. The MQSGA included 7 items: weight change, complications, subcutaneous fat reduction, gastric motility, muscle wasting, and diet change. Each item was scored by 15 scores in 5 grades from no change to extremely severe. The total score was 7-35. The lower the total score, the better the nutrition. $\mathrm{Hb}$ and $\mathrm{RBC}$ were measured by automatic biochemical analyzer.

\section{Complications}

During HD, the nursing staff increased their observation and recorded the complications of patients in the two groups after treatment, including nausea, chest pain, hypotension, hypertension, itching, dryness, muscle cramps, arrhythmia, restless legs, etc.

\section{Statistical analysis}

SPSS22.0 software was used for statistical analysis. The measurement data conforming to the normal distribution were expressed as $(\mathrm{x} \pm \mathrm{s})$ and tested with $\mathrm{t}$ test. Repeated measurement data were analyzed by repeated measurement variance and tested with $\mathrm{F}$ test. Comparison of multiple groups was performed using single factor variance. Comparison of two groups was performed by q test; $\chi^{2}$ test was used for comparison of count data; rank sum test was used for comparison of rank data. $\mathrm{P}<0.05$ indicated a statistically significant difference.

\section{Results}

\section{Comparison of vascular calcification in the three HD groups}

Based on the vascular calcification scores of the patients in the joint group that there were 14 cases $(56.00 \%)$ of no vascular calcification and 11 cases $(44.00 \%)$ of vascular calcification, comprising 3 cases $(12.00 \%)$ of mild calcification, 4 cases $(16.00 \%)$ of moderate calcification, and 4 cases $(16.00 \%)$ of severe calcification. Vascular calcification in the joint group was better than in the lowflux and high-flux groups $(\mathrm{P}<0.05)$, as shown in Table 2 and Figures 1-3.

\section{Comparison of PTH clearance in the three HD groups before and after treatment}

The serum PTH and $\beta 2-M G$ concentrations of the patients in the joint group after treatment decreased compared with the low-flux and high-flux groups $(\mathrm{P}<0.05)$, as shown in Table 3 and Figures 4,5.

\section{Comparison of microinflammation status of patients in the three HD groups before and after treatment}

Levels of IL-6, CRP, and TNF- $\alpha$ were in the order of low- 

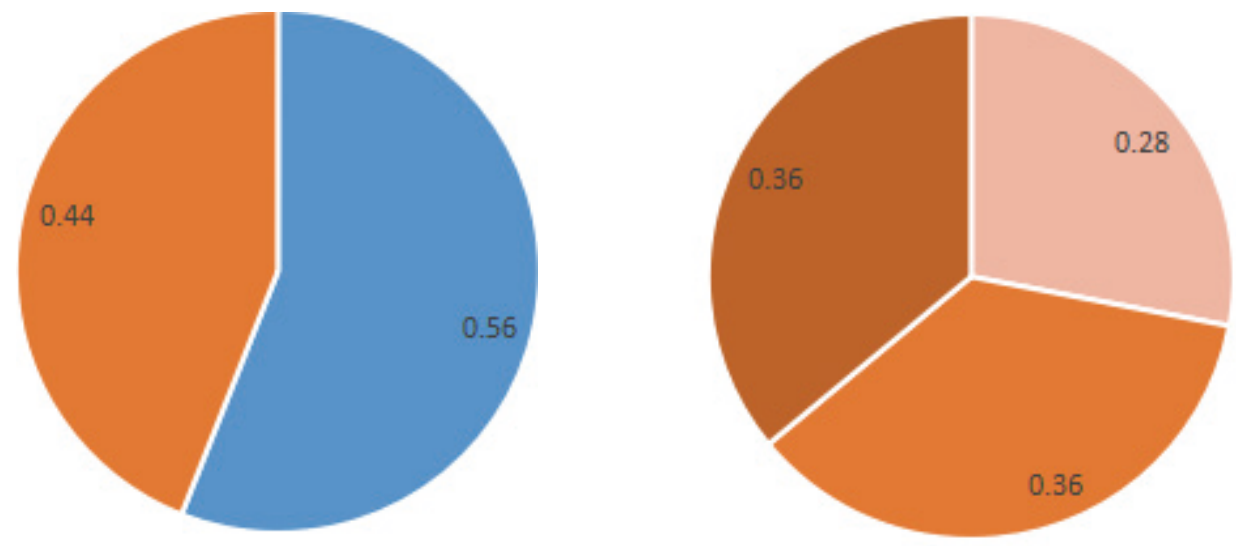

No calcification $=$ Calcification

Mild calcification

Moderate calcification $\quad$ Severe calcification

Figure 1 Vascular calcification in patients in the joint hemodialysis group.
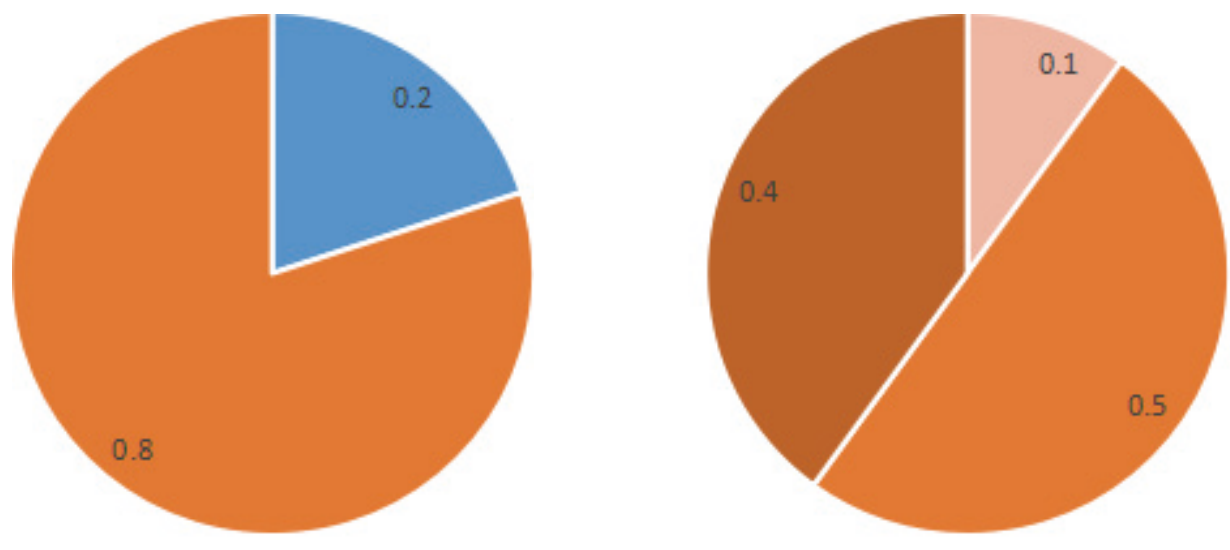

No calcification $\quad$ Calcification

Mild calcification

- Moderate calcification

- Severe calcification

Figure 2 Vascular calcification in the patients in the high-flux hemodialysis group.

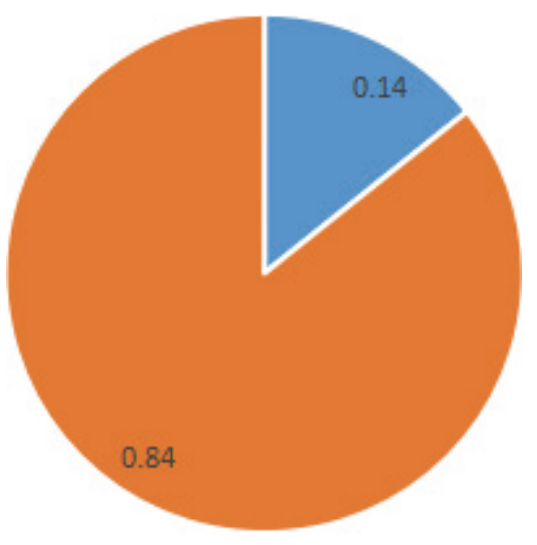

No calcification Calcification
Mild calcification

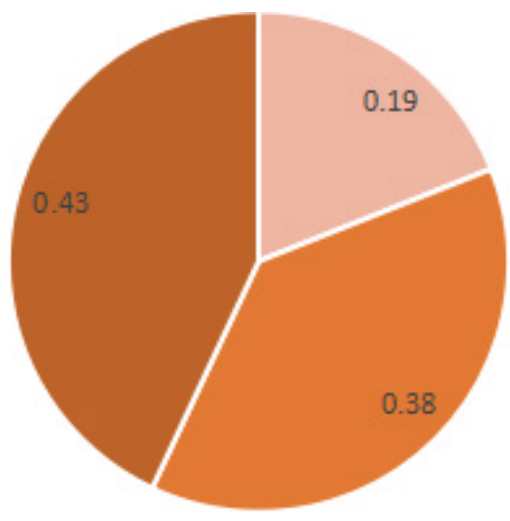

Moderate calcification

- Severe calcification

Figure 3 Vascular calcification in the patients in the low-flux hemodialysis group. 
Table 3 Comparison of parathyroid hormone (PTH) clearance of patients in three HD groups before and after treatment

\begin{tabular}{lccc}
\hline Group & Time & PTH $(\mathrm{ng} / \mathrm{L})$ & $\beta 2-\mathrm{MG}(\mathrm{mg} / \mathrm{L})$ \\
\hline Joint $(\mathrm{n}=25)$ & Before treatment & $456.78 \pm 77.58^{\mathrm{a} 1}$ & $21.06 \pm 2.98^{\mathrm{a} 2}$ \\
& After treatment & $223.29 \pm 45.49^{\mathrm{c} 1}$ & $11.27 \pm 2.63^{\mathrm{c} 2}$ \\
& $\mathrm{t}$ & 12.98 & 12.31 \\
& $\mathrm{P}$ & $<0.05$ & $<0.05$ \\
High-flux HD & Before treatment & $456.16 \pm 73.11^{\mathrm{b} 1}$ & $21.76 \pm 3.01^{\mathrm{b} 2}$ \\
$(\mathrm{n}=25)$ & After treatment & $364.06 \pm 56.05^{\mathrm{d} 1}$ & $15.58 \pm 1.67^{\mathrm{d} 2}$ \\
& $\mathrm{t}$ & 4.99 & 8.97 \\
& $\mathrm{P}$ & $<0.05$ & $<0.05$ \\
Low-flux HD & Before treatment & $459.10 \pm 58.47$ & $21.32 \pm 3.76$ \\
$(\mathrm{n}=25)$ & After treatment & $399.16 \pm 58.07$ & $17.28 \pm 3.48$ \\
& $\mathrm{t}$ & 3.63 & 3.94 \\
& $\mathrm{P}$ & $<0.05$ & $<0.05$ \\
\hline
\end{tabular}

Note: $\mathrm{F}=0.01$ and $\mathrm{F}>0.05$ by comparing the $\mathrm{PTH}$ of the three groups before treatment; $\mathrm{F}=75.71$ and $\mathrm{P}<0.05$ by comparing the PTH of the three groups after treatment; $F=0.29$ and $F>0.05$ by comparing the $\beta 2-\mathrm{MG}$ of the three groups before treatment; $\mathrm{F}=32.99$ and $\mathrm{P}<0.05$ by comparing the $\beta 2-\mathrm{MG}$ of the three groups after treatment. Before treatment, ta $1=0.02$ and 0.11 respectively and ${ }^{\text {a1 }} \mathrm{F}>0.05$ compared with the low-flux and highflux groups; tb1 $=0.15$ and ${ }^{\mathrm{b} 1} \mathrm{~F}>0.05$ compared with the lowflux HD group. After treatment, tc $1=9.75$ and 11.92 respectively and ${ }^{c 1} \mathrm{P}<0.05$ compared with the low-flux and high-flux groups; td1 $=2.17$ and ${ }^{d 1} \mathrm{P}<0.05$ compared with the low-flux HD group. Before treatment, ta2 $=0.82$ and 0.27 respectively and ${ }^{22} \mathrm{~F}>0.05$ compared with the low-flux and high-flux groups; tb2 $=0.45$ and ${ }^{\mathrm{b} 2} \mathrm{~F}>0.05$ compared with the low-flux HD group. After treatment, tc2 $=6.91$ and 6.88 respectively and ${ }^{\mathrm{c} 2} \mathrm{P}<0.05$ compared with the low-flux and high-flux groups; td $2=2.20$ and ${ }^{\mathrm{d} 2} \mathrm{P}<0.05$ compared with the low-flux HD group. HD, hemodialysis.

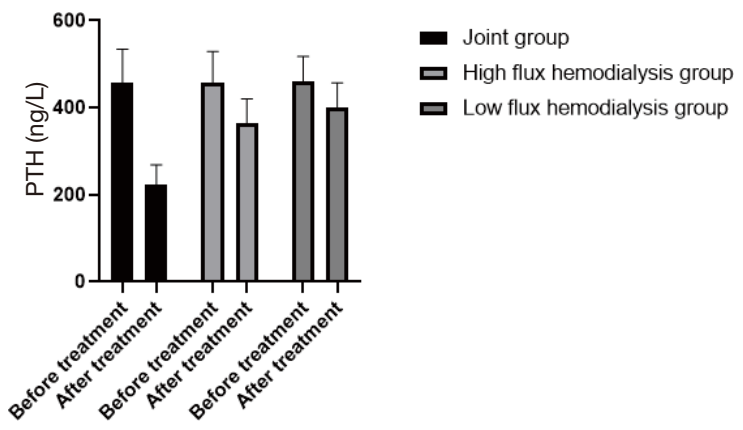

Figure 4 Comparison of parathyroid hormone (PTH) levels of patients in the three HD groups before and after treatment. HD, hemodialysis.

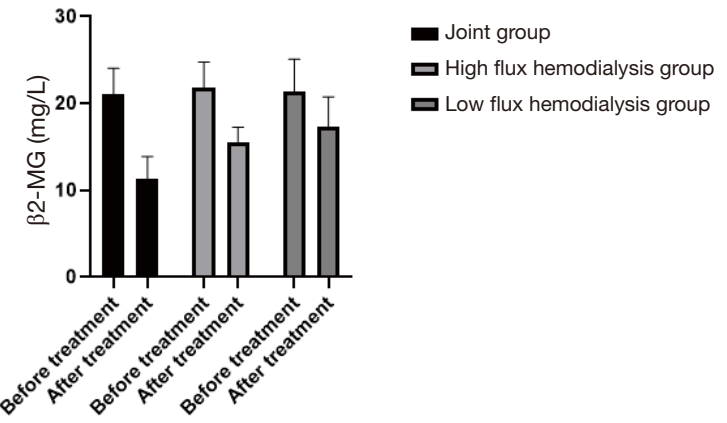

Figure 5 Comparison of $\beta 2$-microglobulin ( $\beta 2-M G$ ) levels of patients in the three HD groups before and after treatment. HD, hemodialysis.

flux HD group $<$ high-flux HD group $<$ joint group $(\mathrm{P}<0.05)$ after treatment, as shown in Table 4, and Figures 6-8. Levels in the joint group decreased significantly $(\mathrm{P}<0.05)$.

\section{Comparison of levels of plasma bepcidin in patients in the three HD groups before treatment}

Levels of hepcidin in the patients were in the order of lowflux HD group $<$ high flux HD group $<$ joint group $(\mathrm{P}<0.05)$ after treatment, as shown in Table 5, and Figure 9. Levels in the joint group decreased significantly $(\mathrm{P}<0.05)$.

\section{Comparison of nutritional status of the patients in the three HD groups before and after treatment}

Average MQSGA score after treatment was lower in the joint group, and both $\mathrm{Hb}$ and $\mathrm{RBC}$ were higher than in the low- and high-flux HD groups $(\mathrm{P}<0.05)$, as shown in Table 6 , and Figures 10-12.

\section{Comparison of complications in the patients in the three HD groups after treatment}

There was no statistically significant difference in the incidence rate of complications in patients in the three HD groups ( $\mathrm{F}>0.05)$, as shown in Table 7 and Figure 13.

\section{Discussion}

Research has shown that the kidney volume of people aged over 80 years decreases by $18.1 \%$, the glomeruli suffer from physiological sclerosis, and the glomerular filtration rate shows a physiological decline (6). Advanced age increases 
Table 4 Comparison of microinflammation status of patients in the three HD groups before and after treatment

\begin{tabular}{|c|c|c|c|c|}
\hline Group & Time & IL-6 (pg/mL) & CRP (mg/L) & TNF- $\alpha$ (ng/L) \\
\hline \multirow[t]{4}{*}{ Joint $(n=25)$} & Before treatment & $91.39 \pm 5.79^{\mathrm{a} 1}$ & $8.83 \pm 1.77^{\mathrm{a} 2}$ & $42.87 \pm 4.01^{\mathrm{a} 3}$ \\
\hline & After treatment & $42.96 \pm 3.94^{\mathrm{c} 1}$ & $3.34 \pm 0.49^{\mathrm{c} 2}$ & $24.03 \pm 2.64^{\mathrm{c3}}$ \\
\hline & $\mathrm{t}$ & 34.57 & 14.94 & 19.62 \\
\hline & $\mathrm{P}$ & $<0.05$ & $<0.05$ & $<0.05$ \\
\hline \multirow{3}{*}{ High-flux HD (n=25) } & After treatment & $53.87 \pm 3.66^{\mathrm{d} 1}$ & $4.38 \pm 0.61^{\mathrm{d} 2}$ & $29.45 \pm 2.35^{\mathrm{d} 3}$ \\
\hline & $\mathrm{t}$ & 29.82 & 14.12 & 15.26 \\
\hline & $\mathrm{P}$ & $<0.05$ & $<0.05$ & $<0.05$ \\
\hline \multirow[t]{2}{*}{ Low-flux HD (n=25) } & Before treatment & $90.82 \pm 5.15$ & $8.85 \pm 1.50$ & $41.45 \pm 3.62$ \\
\hline & $\mathrm{P}$ & $<0.05$ & $<0.05$ & $<0.05$ \\
\hline
\end{tabular}

Note: $F=0.11,0.001$, and 1.03 respectively and $F>0.05$ by comparing the IL- $6, C R P$, and TNF- $\alpha$ of the three groups before treatment; $\mathrm{F}=179.16,131.81$, and 48.63 and $\mathrm{P}<0.05$ by comparing the IL-6, CRP, and TNF- $\alpha$ of the three groups after treatment. Before treatment, ta1 $=0.42$ and 0.36 respectively and ${ }^{a 1} \mathrm{~F}>0.05$ compared with the low-flux and high-flux groups; tb1 $=0.05$ and ${ }^{\mathrm{b} 1} \mathrm{~F}>0.05$ compared with the low-flux HD group. After treatment, tc $1=10.14$ and 17.33 respectively and ${ }^{c 1} \mathrm{P}<0.05$ compared with the low-flux and high-flux groups; td $1=9.88$ and ${ }^{\mathrm{d} 1} \mathrm{P}<0.05$ compared with the low-flux HD group. Before treatment, ta2 $=0.04$ and 0.04 respectively and ${ }^{\mathrm{a} 2} \mathrm{~F}>0.05$ compared with the low-flux and high-flux groups; tb2 $=0.00$ and ${ }^{\mathrm{b} 2} \mathrm{~F}>0.05$ compared with the low-flux HD group. After treatment, tc2 $=6.64$ and 15.85 respectively and ${ }^{\mathrm{c} 2} \mathrm{P}<0.05$ compared with the low-flux and high-flux groups; td2 $=9.30$ and ${ }^{\mathrm{d} 2} \mathrm{P}<0.05$ compared with the low-flux $\mathrm{HD}$ group. Before treatment, ta3 $=0.20$ and 1.31 respectively and ${ }^{a 3} \mathrm{~F}>0.05$ compared with the low-flux and high-flux groups; tb3 $=1.17$ and ${ }^{\mathrm{b} 3} \mathrm{~F}>0.05$ compared with the low-flux HD group. After treatment, tc $3=7.66$ and 8.78 respectively and ${ }^{c 3} \mathrm{P}<0.05$ compared with the low-flux and highflux groups; td3 $=3.65$ and ${ }^{\mathrm{d} 3} \mathrm{P}<0.05$ compared with the low-flux HD group. CRP, C-reactive protein; IL, interleukin; TNF, tumor necrosis factor.

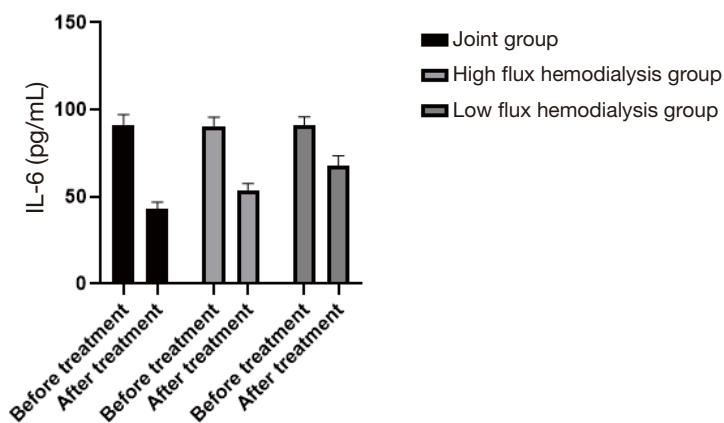

Figure 6 Comparison on of interleukin (IL)-6 levels of patients in the three HD groups before treatment. HD, hemodialysis.

the prevalence of chronic kidney disease (CKD). An estimation by the CKD-EPI formula found an incidence rate of CKD in the population aged over 70 years in the USA of $46.8 \%$ (7). Elderly HD patients accounted for $65 \%$ of the total HD patients in 2009 in the USA (8). A study in

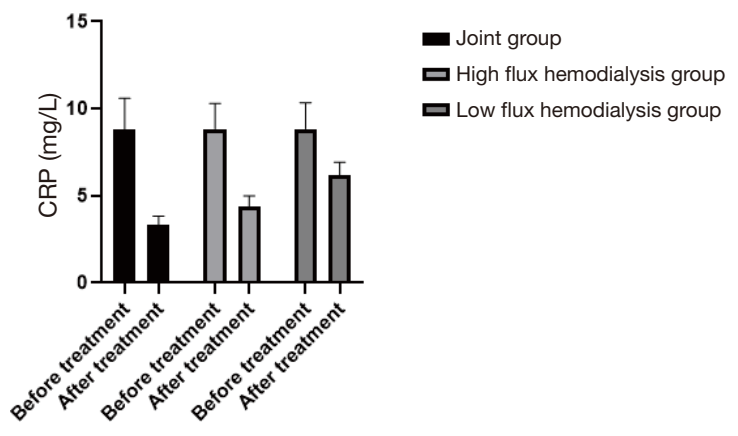

Figure 7 Comparison of C-reactive protein (CRP) levels in patients in the three HD groups before treatment. HD, hemodialysis.

France revealed that elderly HD patients aged over 75 years accounted for $16.5 \%$ of the total number of HD patients, with a maximum age of 94 years (9). And it has been revealed that $51 \%$ of HD patients over the age of 75 years die within 2 years of starting HD (10); the average survival 


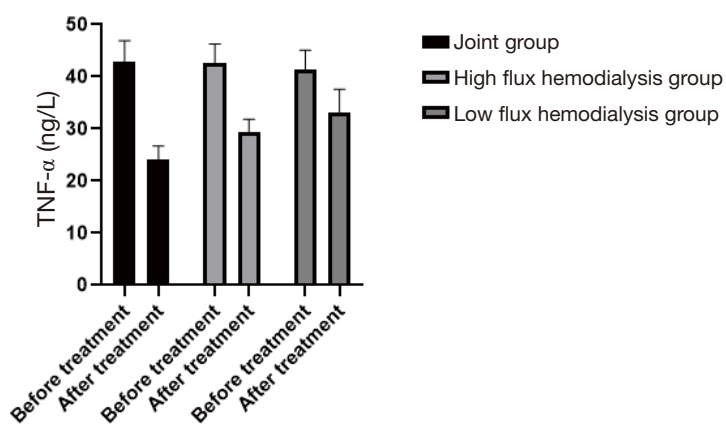

Figure 8 Comparison of tumor necrosis factor alpha (TNF-a) levels of patients in the three HD groups before treatment. HD, hemodialysis.

Table 5 Comparison of levels of plasma hepcidin in patients in the three HD groups before and after treatment

\begin{tabular}{lcccc}
\hline Group & $\begin{array}{c}\text { Before } \\
\text { treatment }\end{array}$ & $\begin{array}{c}\text { After } \\
\text { treatment }\end{array}$ & $q$ & $P$ \\
\hline Joint $(n=25)$ & $21.82 \pm 3.67^{\mathrm{a}}$ & $7.32 \pm 1.07^{\mathrm{c}}$ & $18.96<0.05$ \\
High-flux HD $(\mathrm{n}=25)$ & $21.97 \pm 3.19^{\mathrm{b}}$ & $9.51 \pm 1.62^{\mathrm{d}}$ & $17.41<0.05$ \\
Low-flux HD $(\mathrm{n}=25)$ & $21.58 \pm 3.62$ & $13.94 \pm 3.23$ & $7.87<0.05$ \\
\hline
\end{tabular}

Note: $F=0.07$ and $F>0.05$ of the three groups before treatment; $\mathrm{F}=60.06$ and $\mathrm{P}<0.05$ of the three groups after treatment. Before treatment, ta $=0.15$ and 0.23 respectively and ${ }^{\mathrm{a}} \mathrm{F}>0.05$ compared with the low-flux and high-flux groups; tb $=0.40$ and ${ }^{b} \mathrm{~F}>0.05$ compared with the low-flux HD group. After treatment, tc $=5.64$ and 9.72 respectively and ${ }^{\mathrm{C}} \mathrm{P}<0.05$ compared with the low-flux and high-flux groups; td $=6.12$ and ${ }^{d} \mathrm{P}<0.05$ compared with the low-flux HD group. HD, hemodialysis.

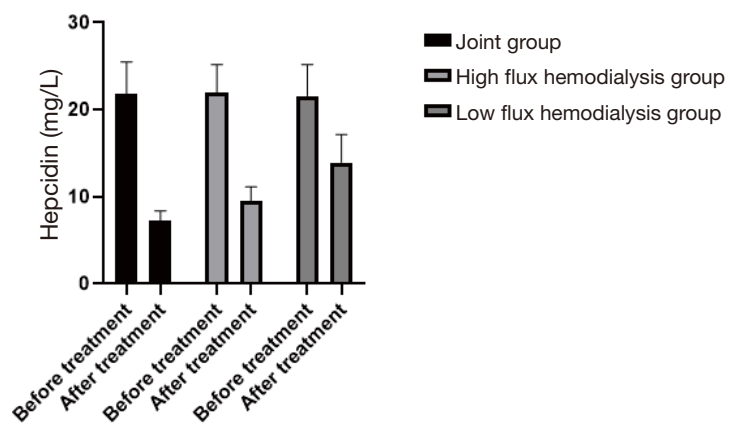

Figure 9 Comparison of the levels of plasma hepcidin in patients in the three HD groups before and after treatment. HD, hemodialysis.
Table 6 Comparison of nutritional status of patients in the three HD groups before and after treatment

\begin{tabular}{|c|c|c|c|c|}
\hline Group & Time & MQSGA (score) & $\mathrm{Hb}(\mathrm{g} / \mathrm{L})$ & $\operatorname{RBC}\left(10^{12} / \mathrm{L}\right)$ \\
\hline \multirow[t]{4}{*}{$\begin{array}{l}\text { Joint } \\
(n=25)\end{array}$} & $\begin{array}{c}\text { Before } \\
\text { treatment }\end{array}$ & $14.90 \pm 2.15^{\mathrm{a} 1}$ & $64.06 \pm 2.24^{\mathrm{a} 2}$ & $2.44 \pm 0.18^{\mathrm{a} 3}$ \\
\hline & $\begin{array}{c}\text { After } \\
\text { treatment }\end{array}$ & $9.83 \pm 1.39^{c 1}$ & $87.98 \pm 2.66^{\mathrm{c} 2}$ & $4.29 \pm 0.14^{\mathrm{c} 3}$ \\
\hline & $\mathrm{t}$ & 9.90 & 34.39 & 40.56 \\
\hline & $\mathrm{P}$ & $<0.05$ & $<0.05$ & $<0.05$ \\
\hline \multirow{4}{*}{$\begin{array}{l}\text { High- } \\
\text { flux HD } \\
(n=25)\end{array}$} & $\begin{array}{c}\text { Before } \\
\text { treatment }\end{array}$ & $14.30 \pm 2.23^{b 1}$ & $63.36 \pm 2.86^{\mathrm{b} 2}$ & $2.45 \pm 0.21^{\mathrm{b} 3}$ \\
\hline & $\begin{array}{c}\text { After } \\
\text { treatment }\end{array}$ & $12.44 \pm 1.86^{\mathrm{d} 1}$ & $81.72 \pm 3.85^{\mathrm{d} 2}$ & $3.57 \pm 0.13^{\mathrm{d} 3}$ \\
\hline & $\mathrm{t}$ & 3.20 & 19.14 & 22.67 \\
\hline & $\mathrm{P}$ & $<0.05$ & $<0.05$ & $<0.05$ \\
\hline \multirow{4}{*}{$\begin{array}{l}\text { Low- } \\
\text { flux HD } \\
(n=25)\end{array}$} & $\begin{array}{c}\text { Before } \\
\text { treatment }\end{array}$ & $14.56 \pm 2.04$ & $63.32 \pm 3.54$ & $2.42 \pm 0.19$ \\
\hline & $\begin{array}{c}\text { After } \\
\text { treatment }\end{array}$ & $13.38 \pm 2.27$ & $74.77 \pm 2.55$ & $2.70 \pm 0.12$ \\
\hline & $\mathrm{t}$ & 1.93 & 13.12 & 6.22 \\
\hline & $\mathrm{P}$ & $<0.05$ & $<0.05$ & $<0.05$ \\
\hline
\end{tabular}

Note: $F=0.49,0.50$, and 0.15 respectively and $F>0.05$ by comparing the MQSGA, $\mathrm{Hb}$, and RBC of the three groups before treatment; $F=24.06,115.31$, and 608.73 and $P<0.05$ by comparing the MQSGA, $\mathrm{Hb}$, and $\mathrm{RBC}$ of the three groups after treatment. Before treatment, ta $1=0.96$ and 0.57 respectively and ${ }^{\text {a1 }} \mathrm{F}>0.05$ compared with the low-flux and high-flux groups; tb1 $=0.43$ and ${ }^{b 1} F>0.05$ compared with the low-flux HD group. After treatment, tc1 $=5.62$ and 6.62 respectively and ${ }^{c 1} \mathrm{P}<0.05$ compared with the low-flux and high-flux groups; td $1=1.60$ and ${ }^{d 1} \mathrm{~F}>0.05$ compared with the low-flux HD group. Before treatment, ta2 $=0.96$ and 0.88 respectively and ${ }^{{ }^{2} 2} \mathrm{~F}>0.05$ compared with the low-flux and high-flux groups; tb2 $=0.04$ and ${ }^{\mathrm{b} 2} \mathrm{~F}>0.05$ compared with the low-flux HD group. After treatment, tc2 $=6.68$ and 17.92 respectively and ${ }^{c 2} \mathrm{P}<0.05$ compared with the low-flux and high-flux groups; td2 $=7.52$ and ${ }^{\mathrm{d} 2} \mathrm{P}<0.05$ compared with the low-flux HD group. Before treatment, ta3 $=0.18$ and 0.38 respectively and ${ }^{2}{ }^{3} \mathrm{~F}>0.05$ compared with the low-flux and high-flux groups; tb3 $=0.52$ and ${ }^{\mathrm{b} 3} \mathrm{~F}>0.05$ compared with the low-flux HD group. After treatment, tc3 $=18.84$ and 43.11 respectively and ${ }^{c 3} \mathrm{P}<0.05$ compared with the low-flux and high-flux groups; td $3=24.58$ and ${ }^{\mathrm{d} 3} \mathrm{P}<0.05$ compared with the low-flux HD group. HD, hemodialysis. 


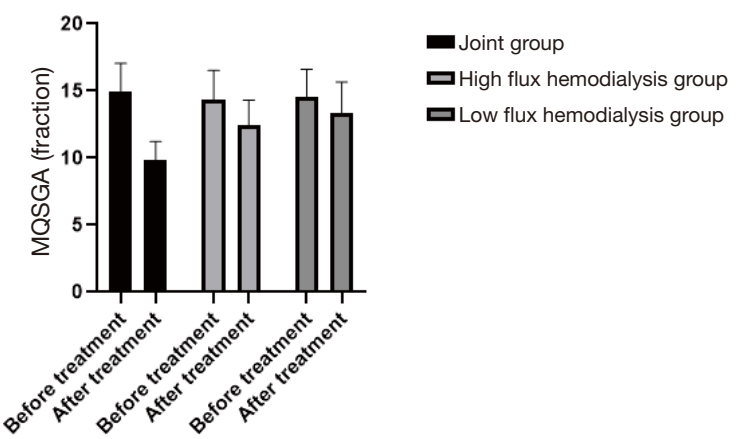

Figure 10 Comparison of modified quantitative subjective global assessment (MQSGA) scores of patients in the three HD groups before and after treatment. HD, hemodialysis.

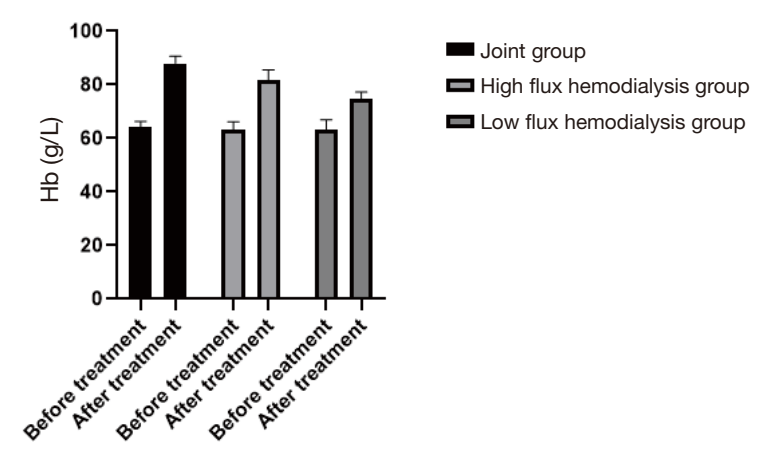

Figure 11 Comparison of hemoglobin $(\mathrm{Hb})$ levels of patients in the three HD groups before and after treatment. HD, hemodialysis.

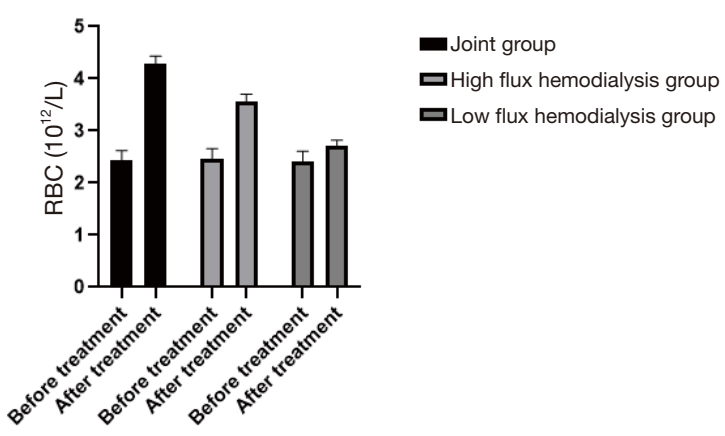

Figure 12 Comparison of red blood cell (RBC) levels of patients in the three HD groups before and after treatment. HD, hemodialysis.

time of MHD patients aged over 80 years was 25.1 months. Compared with younger patients, elderly patients will suffer from more complications after $\mathrm{HD}$, and the average
Table 7 Comparison of complications in patients in the three HD groups after treatment

\begin{tabular}{lcccccc}
\hline Complications & $\begin{array}{c}\text { Joint group } \\
(\mathrm{n}=25)\end{array}$ & $\begin{array}{c}\text { High-flux } \\
\text { HD group } \\
(\mathrm{n}=25)\end{array}$ & $\begin{array}{c}\text { Low-flux HD } \\
\text { group }(\mathrm{n}=25)\end{array}$ & $\chi^{2}$ & $\mathrm{P}$ \\
\hline Nausea & 1 & 2 & 2 & - & - \\
Chest pain & 1 & 2 & 2 & - & - \\
Hypotension & 1 & 1 & 1 & - & - \\
Hypertension & 2 & 1 & 2 & - & - \\
Itching & 1 & 1 & 1 & - & - \\
Dryness & 1 & 1 & 2 & - & - \\
Muscle spasm & 0 & 1 & 1 & - & - \\
Arrhythmia & 0 & 1 & 0 & - & - \\
Restless leg & 0 & 0 & 1 & - & - \\
Total & $7(0.28)$ & $10(0.40)$ & $12(0.48)$ & $2.13>0.05$ \\
\hline
\end{tabular}

HD, hemodialysis.

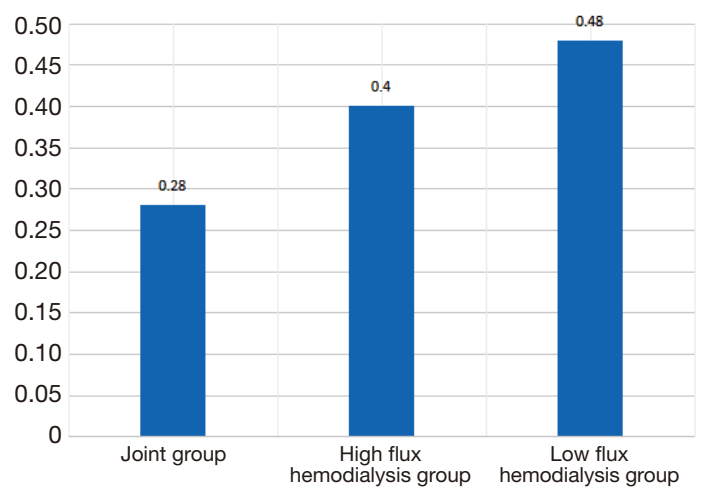

Figure 13 Comparison of complications in patients in the three HD groups after treatment. HD, hemodialysis.

hospitalization rate and hospitalization costs increase greatly. Thus, improving the HD management of elderly patients will contribute to reducing the economic burden of both society and families (11).

HD is a key treatment for prolonging the life of uremic patients, and how to improve the QOL for uremic dialysis patients has become a crucial topic. In order to correctly implement high-flux dialysis, doctors need to conduct comprehensive pre-hemodialysis evaluations on patients, and strictly require patients to meet the high-flux dialysis indications; high-flux dialysis operators must be qualified after professional training and strictly refer to high-flux 
dialysis Requirements and procedures for high-throughput dialysis treatment of patients. Complications such as anemia, microinflammatory state, malnutrition, and vascular calcification are the major factors affecting QOL of HD patients (12). The incidence of anemia in MHD patients is related to the relative lack of erythropoietin, the presence of erythropoietin inhibitory factors, and the increase in erythrocyte fragility in the kidneys of uremia patients. Anemia has a positive correlation with death of MHD patients (13). In normal people, the expression level of hepcidin in the body is relatively low, but when there is a high iron load, inflammation, or erythropoiesis, the level of hepcidin will increase. Hepcidin can inhibit the movement of iron in vascular wall macrophages, and increase the vascular damage. If the iron level in macrophages at the site of vascular damage is too high or is deposited, it will cause oxidative stress, further accelerating atherosclerosis (14).

Microinflammation relates to the release of proinflammatory factors. It is manifested by a slight but continuous increase of inflammatory cytokines in the circulation, although the patient shows no signs of clinical infection. It can aggravate renal failure, cause atherosclerosis and malnutrition, and increase the mortality rate of patients. Thus, the microinflammatory status is an important indicator reflecting the prognosis of patients (15). Malnutrition is an independent risk factor for the mortality and morbidity of HD patients, especially elderly patients. The elderly patients suffer from significantly reduced immunity to external harmful factors, and also poor nutritional state due to deterioration in body functions, so that they suffer from more complications (16). Therefore, the QOL of patients with uremic HD can be increased by improving all of the described factors.

This study revealed that the PTH level, vascular calcification, hepcidin, and nutritional status of patients in the high-flux HD group were higher than those in the low-flux HD group after treatment. High-flux HD can increase the plasma $\mathrm{Hb}$ level by removing more cytokines that may inhibit protein synthesis and appetite, alleviate stimulation of inflammatory factors, enhance the clearance of intermediate molecular substances, decrease leptin level, improve appetite, and promote gastrointestinal motility (17). High-flux HD can slow the progression of hyperparathyroidism-related nephropathy by reducing the PTH level. In addition, high-flux HD can not only reduce the accumulation of $\beta 2$ microglobulin, but also effectively relieve dialysis-related amyloidosis. Thus, it can significantly improve lipid metabolism, reduce oxidative stress, improve the microinflammatory state, and correct the nutritional status (18).

High-flux HD can correct malnutrition by reducing serum PTH levels to decrease its effects on bone metabolism and anemia (19). Research results have revealed that correctly performed high-flux HD can improve the efficiency of dialysis and thus the nutritional status (20). Compared with low-flux HD, the advantages of high-flux HD are very apparent. Solute removal under the principles of dispersion, convection, and adsorption can enhance the removal of medium and large molecular toxins or block their biological effects, improve the stability of albumin, and significantly improve the anemia, nutritional, and microinflammatory status of MHD patients. Thus, the high flux HD treatment is more beneficial for elderly MHD patients (21). Excessive clearance of cytokines by high-flow HD may affect the body, such as aggravating malnutrition, anemia, etc., but there is no significant difference in the complications of the patients in this study. Therefore, the patient's condition should be accurately evaluated before dialysis and the operation should be strictly followed requirements to perform high-flow HD correctly may not cause obvious damage to the patients.

$\mathrm{L}-\mathrm{CN}$ is a special amino acid, mainly expressed in the body tissues, and is essential for mammals during energy metabolism. L-CN is mainly produced from animal food, and is partially synthesized in the spleen and liver. It is mainly used to promote the normal circulation of tricarboxylic acid in the body and provide the energy to cells to maintain normal physiological activities of the body (22). Although animal foods may produce L-CN, animal foods contain few L-CN. Supplementing L-CN with animal foods often cannot meet the needs of the body, and animal foods may contain substances that may aggravate the disease severity of dialysis patients. Therefore, it is necessary to supplement $\mathrm{L}-\mathrm{CN}$ with drugs. In elderly patients on MHD, renal function is continuously exhausted, so L-CN synthesis is significantly reduced. At the same time, intake of carnitine-rich foods is decreased, and because the relative molecular weight of L-CN is not high, it is easily dissolved in water and cleared during MHD. As a result, the patient is extremely lacking in carnitine, which can affect the oxidation of free fatty acids in the mitochondria and their accumulation in the cytoplasm. Thus, $\mathrm{L}-\mathrm{CN}$ is unable to intervene in the normal circulation process of tricarboxylic acid, resulting in a serious lack of energy in the body. Therefore, 
deficiency of L-CN can aggregate anemia and malnutrition in MHD patients. However, L-CN injection can significantly alleviate the inflammatory response in MHD patients, improve anemia and malnutrition, and improve QOL of patients. Thus, its clinical application value is outstanding (23). Currently, some researchers (24) have revealed that $\mathrm{L}-\mathrm{CN}$ has antioxidant and anti-inflammatory effects. It can inhibit the activity of c-jun $\mathrm{N}$-terminal kinase by reducing the expression level of phosphorylated protein in peripheral blood monocytes, thereby inhibiting the generation of pro-inflammatory factors. L-CN can not only enhance the metabolism of fatty acids in the body, but also increase the supply of cellular energy to lower proteolysis and sarcolysis, and thereby improve the nutritional state of MHD patients. The pathological mechanism of L-CN improving the microinflammation and malnutrition of elderly MHD patients has two aspects. Firstly, after supplementation with $\mathrm{L}-\mathrm{CN}$, the quality of anabolic protein in the body is significantly improved, catabolism is reduced greatly, synthesis of albumin is enhanced, concentrations of albumin and $\mathrm{Hb}$ are increased, and the appetite of the patient is better. Thus, the intake of protein and calories are increased, the use of fat is improved, and the physical fitness of the patient is enhanced. In addition, the body's metabolism is a virtuous cycle, and immune resistance to inflammation is enhanced (25). Secondly, L-CN up-regulated the activity of glucocorticoid receptors on the cell membrane surface, reduced the mass release of pro-inflammatory factors, conduct the cascade activation through specific cell signal caused by oxidative stress and pro-inflammatory factors, enhanced the cell defense against oxidative stress and chronic inflammation, and inhibited the production of CRP (26).

Zhang et al. [2015] has shown that L-CN has a protective effect on cell membranes, and can prolong the survival time of RBCs by enhancing the stability of their membranes. What's more, L-CN can stabilize the erythrocyte skeleton, and strengthen erythrocyte membrane contractile proteins and actions, thereby affecting the deformability of the RBC membrane, improving the metabolism and compensatory function of iron, and correcting renal anemia by regulating the level of serum hepcidin (27).

In conclusion, high-flux HD combined with levocarnitine therapy in elderly patients on MHD can safely increase the clearance ability of medium and large molecular toxins, effectively correct malnutrition, relieve the microinflammatory state, and delay the progress of vascular calcification.

\section{Acknowledgments}

Funding: This research was funded by the Zhongshan Science and Technology Bureau Projects (No. 2017B1061).

\section{Footnote}

Reporting Checklist: The authors have completed the CONSORT reporting checklist. Available at http://dx.doi. org/10.21037/apm-21-66

Data Sharing Statement: Available at http://dx.doi. org/10.21037/apm-21-66

Conflicts of Interest: All authors have completed the ICMJE uniform disclosure form (available at http://dx.doi. org/10.21037/apm-21-66). The authors have no conflicts of interest to declare.

Ethical Statement: The authors are accountable for all aspects of the work in ensuring that questions related to the accuracy or integrity of any part of the work are appropriately investigated and resolved. All procedures performed in this study involving human participants were in accordance with the Declaration of Helsinki (as revised in 2013). Informed consent was taken from all the patients. The study was approved by institutional ethics committee of The Affiliated Xiaolan Hospital of Southern Medical University (No. 201709).

Open Access Statement: This is an Open Access article distributed in accordance with the Creative Commons Attribution-NonCommercial-NoDerivs 4.0 International License (CC BY-NC-ND 4.0), which permits the noncommercial replication and distribution of the article with the strict proviso that no changes or edits are made and the original work is properly cited (including links to both the formal publication through the relevant DOI and the license). See: https://creativecommons.org/licenses/by-nc-nd/4.0/.

\section{References}

1. Ha L, Shi JB, Yu HY, et al. Association between serum cartilage oligomeric matrix protein and coronary artery calcification in maintenance hemodialysis patients. J Geriatr Cardiol 2020;17:67-73.

2. Bichu S, Tilve P, Kakde P, et al. Relationship between the use of aluminium utensils for cooking meals and 
chronic aluminum toxicity in patients on maintenance hemodialysis: a case control study. J Assoc Physicians India 2019;67:52-56.

3. James PA, Opafil S, Carter BL, et al. 2014 evidence-based guideline for the management of high blood pressure in adults: report from the panel members appointed to the eight combined national committee (JNC8). JAMA 2014;311:507-20.

4. Higuchi T, Abe M, Yamazaki T, et al. Effects of levocarnitine on brachial-ankle pulse wave velocity in hemodialysis patients: a randomized con-trolled trial. Nutrients 2014;6:5992-6004.

5. Higuchi T, Abe M, Yamazaki T, et al. Levocarnitine improves cardiac function in hemodialysis patients with left ventricular hypertrophy: a randomized controlled trial. Am J Kidney Dis 2016;67:260-70.

6. Sumida K, Yamagata K, Iseki K, et al. Different impact of hemodialysis vintage on cause specific mortality in longterm hemodialysis patients. Nephrol Dial Transplant 2016;31:298.

7. Hsu CY, Me Culloch CE, Curhan GC, et al. Epidemiology of anemia associated with chronic renal hasuffidency among adults in the United States: results from the third national health and nutrition examination survey. J Am Soc Nephrol 2002;13:504-10.

8. Collins AJ, Foley RN, Chavers B, et al. United States renal data system 2011 annual data report. Atlas of chronic kidney disease \& end-stage renal disease in the United states. Am J Kidney Dis 2012;59:el-e420.

9. Apaficio M, Cano N, Chauveau E, et al. Nutritional state of hemodialysis patients: a French nutritional cooperative study. Nephrol Dail Transplant 1999;14:1679-86.

10. Fakhrpour R, Hamid Tayebi Khosroshahi H, Ebrahim K, et al. Effect of sixteen weeks combined Training on FGF23, Klotho, and Fetuin-A levels in patients on maintenance hemodialysis. Iran J Kidney Dis 2020;14:212-8.

11. Sladoje-Martinovic B, Mikolasevic I, Bubie I, et al. Survival of chronic hemodialysis patients over 80 years of age. Clin Interv Aging 2014;9:689-96.

12. Staibano P, Perelman I, Lombardi J, et al. Patient-centred outcomes in anaemia and renal disease: a systematic review. Kidney Dis (Basel) 2020;6:74-84.

13. JPadjen I, Radner H, Öhler L, et al. FRI0133

Understanding Anemia in Rheumatoid Arthritis: the association of hemoglobin and hepcidin levels with clinical disease activity and acute phase response. Ann Rheum Dis 2016;75:476.

14. Jia L, Dong X, Yang J, et al. Effectiveness of hypoxia- inducible factor prolyl hydroxylase inhibitor roxadustat on renal anemia in non-dialysis-dependent chronic kidney disease: a systematic review and meta-analysis. Ann Transl Med 2019;7:720.

15. Tani M, Tanaka S, Takamiya K, et al. Effects of repetitive diet-induced fluctuations in plasma phosphorus on vascular calcification and inflammation in rats with early-stage chronic kidney disease. J Clin Biochem Nutr 2020;66:139-45.

16. Gharekhani A, Khatami MR, Dashti-Khavidaki S, Effects of oral supplementation with omega-3 fatty acids on nutritional state and inflammatory markers in maintenance hemodialysis patients. J Ren Nutr 2014;24:177-85.

17. Jiang X, Ji F, Chen ZW, Huang QL, et al. Comparison of high-flux hemodialysis with hemodialysis filtration in treatment of uraemic pruritus: a randomized controlled trial. Int Urol Nephrol 2016;48:1533-41.

18. Rodrigues VP, Libério SA, Lopes FF, et al. Periodontal state and serum biomarkers levels in hemodialysis patients. J Clin Periodontol 2014;41:862-8.

19. Chan M, Kelly J, Batterham M, et al. Malnutrition (subjective global assessment) scores and sel $31 \mathrm{~m}$ albumin levels, but not body mass index values, at initiation of dialysis are independent predictors of mortality: a 10-year clinical cohort study. J Ren Nutr 2012;22:547-57.

20. Yin P, Song Y, Li J. Soluble transferrin receptor as a marker of erythropoiesis in patients undergoing high-flux hemodialysis. Bosn J Basic Med Sci 2017;17:333-8.

21. Chang JF, Yeh JC, Chiu YL, et al. Periodontal pocket depth, hyperglycemia, and progression of chronic kidney disease: a population-based longitudinal study. Am J Med 2017;130:61-69.e1.

22. Matos IV, Castejon E, Meavilla S, et al. Clinical and biochemical outcome after hydroxocobalamin dose escalation in a series of patients with cobalamin C deficiency. Mol Genet Metab 2013;109:360-5.

23. Cuturic M, Abramson RK, Moran RR, et al. Serum carnitine levels and levocarnitine supplementation in institutionalized Huntington's disease patients. Neurol Sci 2013;34:93-8

24. Reuter SE, Evans AM. Carnitine and acylcarnitines: pharmacokinetic, pharmacological and clinical aspects. Clin Pharmacokinet 2012;51:553-72.

25. Mampilly GT, Mampilly TK, Christopher R, et al. Challenges in diagnosing a metabolic disorder: error of pyruvate metabolism or drug induced. J Child Neurol 2014;29:833-6.

26. Santa KM. Treatment options for mitochondrial myopathy, 
encephalopathy, lactic acidosis, and stroke-like episodes (MELAS) syndrome. Pharmacotherapy 2010;30:1179-96.

27. Zhang J, Dong XJ, Shao YX, et al. Efficacies of erythropoietin combined with vitamin $\mathrm{C}$ in hemodiabysis patients with iron overload and renal anemia. Journal of Wannan Medical College 2015;34:541-3.

(English Language Editor: K. Brown)

Cite this article as: Chi XG, Ma Z, Zhang WB, Cai Q, Chen YZ, Ding DL. Effects of high-flux hemodialysis combined with levocarnitine on vascular calcification, microinflammation, hepcidin, and malnutrition of elderly patients on maintenance hemodialysis. Ann Palliat Med 2021;10(3):3286-3298. doi: 10.21037/apm-21-66 